\title{
Opioid use disorder in Germany: healthcare costs of patients in opioid maintenance treatment
}

\author{
Jens Reimer ${ }^{1,2}$, Tobias Vogelmann ${ }^{3 *}$, Daniel Trümper $^{4}$ and Norbert Scherbaum ${ }^{5}$
}

\begin{abstract}
Background: Opioid Use Disorder (OUD) is a substance use disorder with a chronic course associated with comorbid mental and somatic disorders, a high burden of psychosocial problems and opioid maintenance treatment (OMT) as a standard treatment. In the US, OUD imposes a significant economic burden on society, with annual societal costs estimated at over 55 billion dollars. Surprisingly, in Europe and especially in Germany, there is currently no detailed information on the healthcare costs of patients with OUD. The goal of the present research is to gather cost information about OUD patients in OMT with a focus on maintenance medication and relapses.

Methods: We analysed health claims data of four million persons covered by statutory health insurance in Germany, applying a cost-of-illness approach and aimed at examining the direct costs of OMT patients in Germany. Patients with an ICD-10 code F11.2 and at least one claim of an OMT medication were stratified into the treatment groups buprenorphine, methadone or levomethadone, based on the first prescription in each of the follow-up years. Costs were stratified for years with and without relapses. Group comparisons were performed with ANOVA.

Results: We analysed 3165 patient years, the total annual sickness funds costs were on average $7470 €$ per year and patient. Comparing costs of levomethadone ( $8400 €$, SD: 11,080 €), methadone (7090 €, SD: 10,900 $€$ ) and buprenorphine (6670 $€, S D: 7430 €$ ) revealed significant lower costs of buprenorphine compared to levomethadone $(p<0.0001)$. In years with relapses, costs were higher than in years without relapses (8178 € vs $7409 € ;$ SD: 11,622, resp. 10,378 €). In years with relapses, hospital costs were the major cost driver.

Conclusions: The present study shows the costs of OUD patients in OMT for the first time with a German dataset. Healthcare costs for patients with an OUD in OMT are associated with more than two times the cost of an average German patients. Preventing relapses might have significant impact on costs. Patients in different OMT were dissimilar which may have affected the cost differences.
\end{abstract}

Keywords: Opioid use disorder, Opioid maintenance therapy, Buprenorphine, Levomethadone, Methadone, Cost of illness

\section{Background}

Opioid use disorder (OUD) is a substance use disorder characterized by compulsive opioid use, typically resulting in the development of tolerance and withdrawal after stopping the intake of the drug. Currently, there are several options available for the treatment of OUD, including behavioral therapies, opioid maintenance therapy using full opioid agonists (e.g. methadone), partial $\mu$ -

\footnotetext{
* Correspondence: tv@link-care.de

${ }^{3}$ LinkCare GmbH, Stuttgart, Germany

Full list of author information is available at the end of the article
}

opioid agonists (buprenorphine) or medication assisted treatment with opioid antagonists (naltrexone).

OUD imposes a significant economic burden on society in the US, with annual societal costs estimated between 55 billion dollars in 2007 [1] and 78.5 billion dollars in 2013 [2]. The majority of these costs are attributable to lost work productivity (46\%) and healthcare costs (45\%), with criminal justice costs (9\%) making up the balance [1]. Florence et al. attribute $4 \%$ of 2013 costs to substance abuse treatment, $33 \%$ to healthcare, and $26 \%$ to lost productivity for nonfatal cases [2]. The

(c) The Author(s). 2019 Open Access This article is distributed under the terms of the Creative Commons Attribution 4.0 International License (http://creativecommons.org/licenses/by/4.0/), which permits unrestricted use, distribution, and 
remaining costs comprise lost productivity and healthcare for fatal cases (27\%) as well as costs for criminal justice (10\%). An additional burden of OUD are increased healthcare costs due to comorbid somatic diseases and mental disorders.

In a previous study, based on pharmacy and medical claims of 16 self-insured employer health plans in the US in the period of 1998 to 2002, opioid users were compared to a control group of non-abusers. Among these insured individuals, opioid abusers had higher rates of medical and pharmacy utilization and an increased number of comorbidities including poisoning, hepatitis, psychiatric illnesses, and pancreatitis. Healthcare expenditure for these individuals may have been as much as 8 times the total as non-drug users [3].

In Europe, and especially in Germany, there are currently no detailed information about healthcare costs of OUD patients. Available research with regards to Germany, the Netherlands and Switzerland, that investigated the costs of treatment with heroin and methadone, was based on calculations using various assumptions. Due to the lack of data availability, it mainly used administrative costs, such as diagnosis related groups (DRG) costs or listed pharmaceutical prices [4].

Therefore, to analyze healthcare costs of OUD patients in OMT, we designed a retrospective cost analysis in the German healthcare system from the statutory health insurance's (SHI) perspective. The objective of the present study was to examine the overall healthcare costs of OUD patients in OMT using four cost categories: inpatient costs, outpatient costs, pharmacy costs and other costs that included sick pay, aids and remedies, and other medical services.

In Germany, there are currently 78,500 OUD patients in OMT [5]. Methadone, levomethadone and buprenorphine are the most commonly used treatments in OMT [5]. OMT can prevent relapses to illegally acquired opioids [6]. Concerning clinical evidence, it seems that buprenorphine in flexible doses adjusted to patients' need is less effective than methadone (including levomethadone) in terms of treatment retention. For patients retained in treatment, there is no difference in suppression of illicit opioid use as measured by urinalysis or self-report. There are no differences between medium-dose buprenorphine $(7-15 \mathrm{mg})$ and medium-dose methadone $(40-85 \mathrm{mg})$ as to retention or suppression of illicit opioid use. Similarly, there are no differences between high-dose buprenorphine $(\geq 16 \mathrm{mg}$ ) and high-dose methadone ( $\geq 85 \mathrm{mg}$ ) as to retention or suppression of self-reported opioid use [7]. In terms of mortality risks, it seems that buprenorphine could be more effective than methadone in reducing mortality, especially from overdose $[8,9]$.

Up to now, there are mixed findings regarding healthcare costs of different maintenance treatments: A systematic review indicates that pure pharmaceutical costs for methadone are somewhat less costly than buprenorphine [10]. However, previous research showed that although medication costs of buprenorphine might be higher than those of methadone, the overall healthcare costs including hospital and transportation costs may actually be lower [11].

Taken together, the present study addresses the research gap of assessing the overall healthcare costs of patients treated with common opioid maintenance treatments Germany and thus provides a picture of the current cost situation of OMT treated OUD patients in Germany.

\section{Methods}

\section{Study design and data source}

This longitudinal nested case-control cohort study was based on an anonymized German health claims database, including 4 million insureds from 8 German statutory health insurances, that provided a research database that could be used for this study. The dataset included a $5 \%$ sample of overall German population covered by statutory health insurances from January 1, 2010 to December 31, 2015. All patients in the database used for this analysis had complete data across all years of the analysis (2010-2015). Patients with incomplete yearly follow-up data were excluded unless they died within the study period and were in the dataset until death.

The dataset contained information on patients' medical in- and outpatient claims, prescribed and delivered pharmaceuticals and insurance eligibility information. The whole study design was predefined by a detailed analysis protocol following the recommendation of the German society for epidemiology [12].

\section{Inclusion criteria}

Patients with OUD were identified using the International Classification of Diseases, 10th Edition German Modification (ICD-10-GM) code F11.2 (mental and behavioral disorders due to use of opioids, dependence syndrome) in outpatient and/or inpatient care data in any of the quarters in the identification period (Quarter 01/2010 through 04/2011). For inpatient data, primary OUD discharge diagnoses as well as secondary diagnoses were considered. Outpatient physicians are required to designate their diagnoses as one of the following categories: validated, suspected, symptomless condition and excluded. A diagnoses becomes "validated" when it is established beyond doubt, e.g. by a lab test, a specialists' assessment or the physicians' own conclusions [13]. For the current analysis, only validated diagnoses were considered. The index year for each patient was defined as year when the first diagnosis of F11.2 was coded in 2010 or 2011. Although the ICD-10 code for OUD provides no information on the underlying opioid, recent data show that heroin use still accounts for the majority of 
new opioid-related treatment demands in Europe with around $80 \%$ of all patients with OUD [14]. Furthermore, patients needed at least one claim for OMT in the same quarter alongside one OUD diagnosis to be included in the study.

Other diagnoses than OUD were not included in the current analysis, because OMT is by law only available to patients with opioid dependence, not with other opioid abuse diagnoses [15].

\section{Exclusion criteria}

Patients who were prescribed dihydrocodeine, diamorphine, or morphine between 2010 and 2015 were excluded from analyses. Moreover, patients who were younger than 18 years at their first OUD diagnoses in the inclusion period were excluded as they receive abstinence-oriented treatment, not OMT $[16,17]$. Patients with no OMT in a year were excluded from cost analysis in the respective year, unless they had a relapse in the 12-months prior (see section Relapses for details). This was done because this study aimed to examine the healthcare costs of patients within OMT. Costs of OUD patients not in OMT were supposed to mainly occur within sectors outside of the health insurances and therefore not included in the database (e.g. drug counselling or controlled heroin use, both financed by municipalities in Germany or prison stays financed by federal government).

\section{Medical variables}

The dataset included ICD-10-GM codes for all diagnoses given by inpatient or outpatient physicians that were analyzed in each quarter of the inclusion period. Comorbidities were assessed when assigned by a general practitioner or a specialist physician if the ICD-10-GM code was coded as "validated": depression (F32X, F33X), personality disorder (F6X), anxiety (F40X F41.0, F41.1, F41.2), sleeping disorder (F51X), chronic hepatitis C (B18.2), chronic obstructive pulmonary disease (COPD, J44X), HIV/AIDS (B2X) and cardiovascular diseases (I20X-I25X).

\section{Medication variables}

The dataset included Anatomical Therapeutic Chemical Classification (ATC) and pharmaceutical central numbers (PZN) for outpatient drugs prescribed and delivered.

OMT medications delivered to a physician's office for supervised, office-based OMT were analyzed using the ATC codes for methadone, levomethadone, or buprenorphine respectively. OMT medication prescribed for take-home treatment was identified by pharmaceutical central numbers (PZN) from German auxiliary tax (Hilfstaxe) [18].

Table 1 shows the codes used to identify OMT in the different treatment groups.

Patients were stratified in OMT groups with buprenorphine, methadone or levomethadone, based on the
Table 1 Prescriptions of OMT included in the analyses

\begin{tabular}{lll}
\hline & ATC-Codes & $\begin{array}{l}\text { Pharmaceutical central } \\
\text { numbers (PZN) }\end{array}$ \\
\hline $\begin{array}{l}\text { Treatment group } \\
\text { methadone }\end{array}$ & N07 BC02 & 09999086 \\
$\begin{array}{l}\text { Treatment group } \\
\text { levomethadone }\end{array}$ & N07 BC05 & 02567107 \\
$\begin{array}{l}\text { Treatment group } \\
\text { buprenorphine }\end{array}$ & N07 BC01, N07 BC21, & 02567113,02567136 \\
\hline
\end{tabular}

first prescription in each follow-up year. Patients could switch treatment groups in each follow-up year, according to their first prescription in each year, assessed in 12-month periods starting with each patient's earliest relevant drug claim.

\section{Relapses}

The definition of relapses was based on a previous longitudinal cohort study [19] and summarized three sorts of relapses: Firstly, relapse was defined as no OMT treatment for more than three months and returning to OMT thereafter (treatment interruption). Secondly, hospital stays with an acute intoxication defined via ICD-10 code F11.0 (Mental and behavioural disorders due to use of opioids: Acute intoxication) as main or secondary diagnosis were counted as relapse. Thirdly, death was derived from SHI data on the reasons of insurance termination. Reason of death was not included in the database, thus death of all causes was counted as relapse.

For attributing patients' years with and without relapses, hospital stays, and treatment interruptions were counted in the year they started, i.e. hospital stays were counted in the year of the admission stay and treatment interruptions on the first day without OMT medication.

\section{Healthcare costs}

Annual costs from the statutory health insurances database were assessed for each follow-up year and for four different resource use categories: inpatient care (hospital), outpatient care (office, also including outpatient psychotherapy), prescribed pharmaceuticals (outpatient setting only), and other costs that included sick pay, medical aids (e.g. wheelchairs) and remedies (e.g. physical therapy). Total costs were calculated as sum of the four resource use categories. Furthermore, costs were analyzed stratified for years with and without relapses.

\section{Statistical analysis}

Variables were analyzed descriptively using frequencies and percentages for categorical variables and means with standard deviations for continuous variables. Group comparisons at baseline were performed 
using Chi-Squared tests and for categorial and t-tests for continuous variables. Group comparisons between different treatment groups were performed with analysis of variance (ANOVA) and least significant difference (LSD) post hoc tests. A $p$-value of $p<0.05$ was used in all statistical tests for determining statistical significance. We used the software MS Excel 2016 and SAS 9.4, SAS Institute, Cary (North Carolina), USA for statistical analyses.

\section{Results}

\section{Baseline characteristics}

Overall, 996 patients fulfilled the inclusion criteria, 41 of the patients were excluded for being under 18 years old. The remaining 955 patients had a mean age of 37.6 years (standard deviation $(\mathrm{SD})=8.5$ ). For these 955 patients, a total of 3165 patient years in the follow-up period could be observed. In the index year, 350 patients were treated with buprenorphine, 336 with methadone, and 269 patients with levomethadone (see Table 2).

Of 955 patients, 350 (36.66\%) were treated with buprenorphine in the first year, 269 with levomethadone (28.16\%) and 336 with methadone (35.18\%). During follow-up, 23 patients (2.4\%) died of any cause. From these 23 patients, one patient was treated with buprenorphine, 10 patients with levomethadone and 12 with methadone at the time of death.

Seven hundred twenty-seven patients (76.13\%) stayed in OMT treatment during the whole four follow-up years, i.e. had at least one OMT prescription in each year. 59 patients (16.8\%) changed from buprenorphine to methadone during the follow-up, 74 from buprenorphine to levomethadone $(21.1 \%)$. From methadone, 30 patients $(8.9 \%)$ changed to buprenorphine and 89 (26.4\%) to levomethadone. 33 patients who were treated with levomethadone in the index prescription changed to buprenorphine (12.3\%) and 78 changed to methadone (28.9\%).

\section{Clinical characteristics}

Across all treatment groups, the most frequent comorbidities at index date were depression (42.1\%), chronic hepatitis c (38.2\%) and personality disorder (15.0\%) (see Table 3). Overall, there were 2782 patient years without relapses, 349 patient years with relapses as treatment interruption, 22 patient years with relevant hospital stays, and 12 patients deceased during the study period.

\section{Healthcare costs}

Based on the analysis of 3165 patient years, the total annually sickness funds costs for an OUD patient in OMT were on average $7470 €$ per year.

Comparing the 12-months costs of three treatment groups, levomethadone (8400 €, SD: 11,080 €), methadone (7090 €, SD: 10,900 €) and buprenorphine (6670 €, SD: $7430 €)$ revealed significant differences between the treatment groups (ANOVA, $\mathrm{F}=14.19 ; p<0.0001$ ). Post hoc LSD test showed a significant difference between buprenorphine and levomethadone $(\mathrm{t}=24.34 ; \mathrm{p}<$ 0.0001). (see Fig. 1).

For buprenorphine treated patients, the costs were divided in four main cost categories as follows: inpatient costs: $35.01 \%$; $(2335 €)$ outpatient costs: $28.30 \%(1887 €)$; pharmacy costs: $32.41 \%(2162 €)$ and other costs: $4.28 \%$ $(286 €)$. Costs of the methadone group consisted of inpatient costs accounting 38.83\% (2753 €); outpatient costs: $25.02 \%(1774 €)$; pharmacy costs: $28.80 \%(2042 €)$ and other costs: $7.35 \%(521 €)$. And costs of the levomethadone group included $41.84 \%$ inpatient costs (3514 $€), 24.39 \%$ outpatient costs $(2049 €)$; $30.56 \%$ pharmacy costs $(2567 €)$ and $3.21 \%$ other costs $(269 €)$.

We compared treatment costs in years with and without relapses. Results revealed that costs in years with relapses were about $10 \%$ higher than in years without relapses with hospital costs as cost driver $(8178 €$ vs $7409 €$; SD: 11,622, resp. 10,378 €) (see Table 4).

\section{Discussion}

The present study examined overall healthcare costs associated with three different OMT in Germany. The average patient insured via German statutory health insurances induces healthcare costs of around $3034 €$ per year, a value obtained by the risk adjustment scheme of statutory health insurances [20]. We showed that healthcare costs for patients with an OUD in OMT are more than double these costs of an average German patient (7470 $€$ versus $3034 €)$. These healthcare costs should be interpreted as total costs for treating patients with OUD in OMT and should not be interpreted as excess costs of OMT. Also, this number represents the average healthcare costs of

Table 2 Descriptive statistics of the sample population in index year and in following follow-up years

\begin{tabular}{|c|c|c|c|c|c|c|}
\hline Study year & $\begin{array}{l}\text { Index Year } \\
N(\%)\end{array}$ & $\begin{array}{l}\text { Follow-up } 1 \\
N(\%)\end{array}$ & $\begin{array}{l}\text { Follow-up } 2 \\
N(\%)\end{array}$ & $\begin{array}{l}\text { Follow-up } 3 \\
N(\%)\end{array}$ & $\begin{array}{l}\text { Follow-up } 4 \\
N(\%)\end{array}$ & $\begin{array}{l}\text { Patient years in } \\
\text { Follow-up period }\end{array}$ \\
\hline N & 955 & 841 & 804 & 793 & 727 & 3165 \\
\hline OMT with bupren-orphine (\%) & $350(36.6)$ & $302(35.9)$ & $296(36.8)$ & $267(33.6)$ & $250(34.4)$ & $1115(35.2)$ \\
\hline OMT with levo-methadone & $269(28.2)$ & $266(31.6)$ & $271(33.7)$ & $280(35.3)$ & $256(35.2)$ & $1073(33.9)$ \\
\hline OMT with methadone & $336(35.1)$ & $273(32.4)$ & $237(29.4)$ & $246(31.0)$ & $221(30.4)$ & 977 (30.8) \\
\hline
\end{tabular}


Table 3 Baseline characteristics

\begin{tabular}{|c|c|c|c|c|c|}
\hline & Overall $(N=955)$ & buprenorphine $(N=350)$ & methadone $(N=336)$ & levomethadone $(N=269)$ & $p$-value \\
\hline Mean Age (SD) & $33.89(8.3)$ & $33.56(8.5)$ & $34.14(8.2)$ & $34.01(9.1)$ & 0.4681 \\
\hline Male (\%) & $681(71.3)$ & $258(73.7)$ & $243(72.3)$ & $180(66.9)$ & 0.1575 \\
\hline Depression & $402(42.1)$ & $156(44.6)$ & $129(38.4)$ & $117(43.5)$ & 0.2247 \\
\hline Personality Disorder & $143(15.0)$ & $39(11.1)$ & $54(16.1)$ & $50(18.5)$ & 0.0285 \\
\hline Anxiety & $80(8.4)$ & $30(8.6)$ & $26(7.7)$ & $24(8.9)$ & 0.8607 \\
\hline Sleeping Disorder & $118(12.4)$ & $47(13.4)$ & $25(7.4)$ & $46(17.1)$ & 0.0011 \\
\hline Chronic Hepatitis C & $365(38.2)$ & $126(36.0)$ & $124(36.9)$ & $114(42.4)$ & 0.2292 \\
\hline COPD & $63(6.6)$ & $20(5.7)$ & $29(8.6)$ & $14(5.2)$ & 0.1699 \\
\hline HIV/AIDS & $19(2.0)$ & $3(0.9)$ & $11(3.0)$ & $5(1.9)$ & 0.0755 \\
\hline Cardiovascular Diseases & $191(20.0)$ & $66(18.9)$ & $67(19.9)$ & $58(21.56)$ & 0.706 \\
\hline Alcohol Use Disorder & $143(14.9)$ & $49(14.0)$ & $40(11.9)$ & $54(20.1)$ & 0.0162 \\
\hline
\end{tabular}

patients either starting on OMT or continuing a prior course of therapy.

OUD is thus also associated with higher healthcare costs compared to widespread diseases like diabetes mellitus or depression with mean annual costs of $4949 €$ [21] and of $3638 €$, respectively [22]. Costs per year are comparable to patients of chronic non-cancer pain patients in a long-term opioid therapy, where annual costs are around $7603 €[23]$. All cited studies used comparable German SHI claims databases and assessed total healthcare costs, not excess costs, with the same methodological approach used in the current paper.

Extrapolated to the total number of 78,500 OMT patients in Germany [5], costs per year can be estimated to be around 588.4 million $€$ in Germany. Again, these numbers represent overall treatment costs of OMT patients and not costs of OMT treatment per se. The real overall treatment costs are likely to be even higher than this extrapolation, for healthcare costs for privately insured OUD patients might be higher than for patients insured in SHI.

Overall costs for patients in buprenorphine treatment were lower than for those in methadone and levomethadone treatment. These results are in line with a previous study showing cost effectiveness of buprenorphine treatment in case different cost elements are considered [24].

The reason for this could be that buprenorphine can safely be dispensed as take-home doses earlier on in treatment if the patient is at low risk for diversion and can thus be dispensed with less effort [25]. As take-

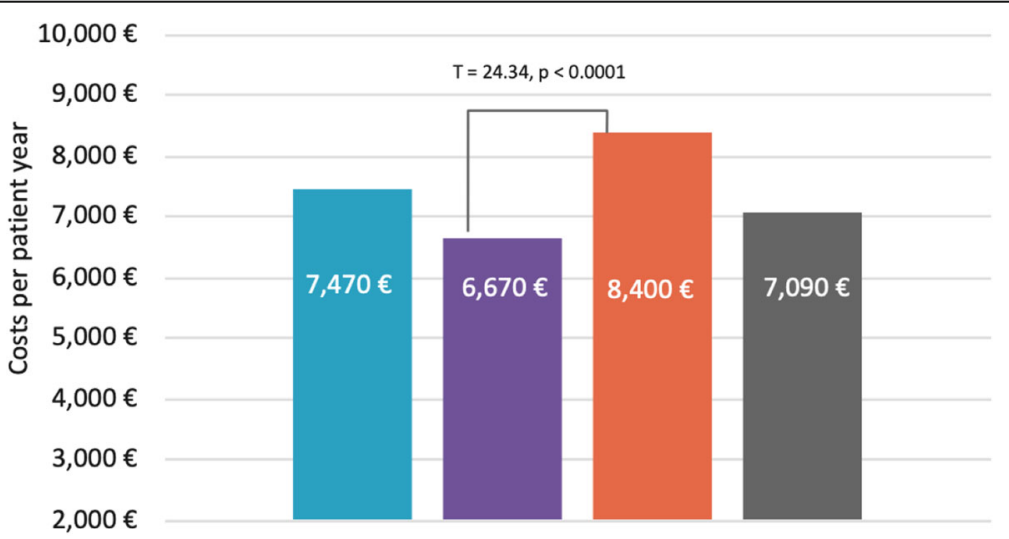

OMT treatments
average
buprenorphine $(\mathrm{N}=1,115$ patient years)
levomethadone
methadone
$(\mathrm{N}=1,073$ patient years)
( $\mathrm{N}=977$ patient years $)$

Fig. 1 Cost comparison of three treatment groups, results of ANOVA 
Table 4 Cost breakdown in years with and without relapses

\begin{tabular}{lll}
\hline & $\begin{array}{l}\text { Patient years } \\
\text { with relapses }\end{array}$ & $\begin{array}{l}\text { Patient years } \\
\text { without relapses }\end{array}$ \\
\hline Hospital costs in Euro (\%) & $4479.94(54.78)$ & $2990.90(40.37)$ \\
Outpatient costs in Euro (\%) & $1765.64(21.59)$ & $1896.87(25.60)$ \\
Pharmaceutical costs in Euro (\%) & $1294.35(15.83)$ & $2199.60(29.69)$ \\
Other costs in Euro (\%) & $638.52(7.81)$ & $321.08(4.33)$ \\
Costs (sum) in Euro & 8178.45 & 7408.45 \\
\hline
\end{tabular}

home treatment is around $30 \%$ less costly than officebased OMT in Germany [26], this could be one factor for lower costs of patients in buprenorphine based OMT. This would be consistent with the shown lower pharmaceutical and outpatient costs of buprenorphine treated compared to levomethadone treated patients. However, also dissimilarities within the different patient groups may have affected the cost differences, since the groups differed in occurance of sleeping disorder and personality disorder at baseline. Frequencies of other diseases associated with high treatment costs such as hepatits $C$ [27] did not differ at baseline.

Costs in years with relapse were $767 €$ (around $10 \%)$ above years without relapses, indicating that preventing relapses might have positive effects on healthcare costs. This is in line with previous research that found associations between relapses and higher healthcare costs in other substance abuse patients: For alcohol addicted patients it was shown that patient groups with a lower risk of relapse also had lower healthcare costs [28].

\section{Strengths and limitations}

The strength of this study is that it used a large sample of the German statutory health insurances to assess healthcare costs directly from a database with health insurance claims data. To our best knowledge, this is the first study to examine costs of patients in OMT in a major European country.

The limitations are as follows:

a) The statutory health insurances database uses billing data which are designed for invoices and not for research activities. Therefore, typically not all necessary information is available, or it has limited quality.

b) Persons entitled to other healthcare funds (e.g. members of the police), but also imprisoned patients are not covered by present data. About 10\% of German population are members of private health insurance companies. There are differences between insureds of statutory and private health insurance companies in their socioeconomic status and health (care) behavior [29]. For this reason, the study sample is not completely representative for the general German population in terms of socioeconomic status. c) We assume that total costs for patients without OMT are higher than indicated by present data because of social costs that are not reflected by statutory health insurances. Previous research [30] pointed out that drug abuse leads to more crime and lower employment. These social costs are not covered by health insurances and were not included in the present study. Moreover, a recent study shows that about one third of overall OUD costs in the US are due to substance abuse treatment costs and about one quarter represent the costs associated with public sector in healthcare, substance abuse treatment, and criminal justice costs [2].

d) There was no randomized assignment to the three drug groups. There is evidence that severely affected patients are more likely to receive methadone than buprenorphine [31, 32]. We did not control for this possible confounder, therefore such dissimilarities may have affected the cost differences.

e) Since the cause of death was not included in the database, death cannot directly be attributed to OUD. The assumption, that every death is counted as a relapse therefore overestimated the number of relapses. Since only $2.4 \%$ of the study population died within follow-up, this should, however, only have little influence on the results.

\section{Conclusions}

In this study we analysed the annual healthcare costs of patients with OUD in opioid maintenance therapy from the perspective of the statutory health insurance in Germany. We showed that costs attributed to patients with an OUD and OMT are more than double the cost of an average patient in Germany. The present study presented costs of OUD for the first time with a large German dataset, comparing patients with different OMT. In sum, we found overall costs for buprenorphine treatment were lower than those for methadone and levomethadone treatment, although the reasons for this need further investigation. Furthermore, preventing relapses might have significant impact on reduction of costs. Which risk groups should be assessed and which OMT and dosages should be used for such relapse prevention, requires further research beyond the scope of this paper.

\footnotetext{
Abbreviations

ANOVA: Analysis of variance; ATC: Anatomical therapeutic chemical classification; COPD: Chronic obstructive pulmonary disease; ICD-10-

GM: International classification of diseases, 10th edition German modification; LSD: Least significant difference; OMT: Opioid maintenance therapy; PZN: Pharmaceutical central numbers; SD: Standard deviation; SHI: Statutory health insurance
}

Acknowledgements

Not applicable. 


\section{Authors' contributions}

Jens Reimer, Tobias Vogelmann, Daniel Trümper and Norbert Scherbaum confirmed to have contributed as per the four points below: Substantial contributions to the conception or design of the work; or the acquisition, analysis, or interpretation of data for the work; AND Drafting the work or revising it critically for important intellectual content; AND Final approval of the version to be published; AND Agreement to be accountable for all aspects of the work.

\section{Funding}

The study was funded by Indivior Deutschland $\mathrm{GmbH}$.

\section{Availability of data and materials}

The study was based on data from the statutory health insurances, which are protected by special data protection law. Restrictions apply to the availability of these data, which were used under license for the current study, and so are not publicly available. Data can be requested from the authors with permission of the involved statutory health insurances.

\section{Ethics approval and consent to participate}

This study was based on previously available and fully anonymized data and did not involve any new studies of human or animal subjects performed by any of the authors. Therefore, no ethics review and approval or informed consent for participants was required. However, approvals from the involved SHIs were obtained to use their data for this study.

\section{Consent for publication}

Not applicable.

\section{Competing interests}

Jens Reimer reports personal fees from Indivior, during the conduct of the study; personal fees from Sanofi-Aventis, personal fees from Hexal, grants and personal fees from Mundipharma, personal fees from Camurus, grants and personal fees from Indivior, outside the submitted work. Norbert Scherbaum reports personal fees from Sanofi-Aventis, personal fees from Indivior, personal fees from AbbVie, personal fees from MSD Pharma, personal fees from Mundipharma, during the conduct of the study. Tobias Vogelmann reports personal fees from Indivior, during the conduct of the study; personal fees from Indivior, outside the submitted work. Daniel Trümper reports personal fees from Indivior.

\section{Author details}

${ }^{1}$ Center for Interdisciplinary Addiction Research, Dept. of Psychiatry and Psychotherapy, University Medical Center Hamburg-Eppendorf, Hamburg, Germany. ${ }^{2}$ Center for Psychosocial Medicine, Health North, Hospital Group Bremen, Bremen, Germany. ${ }^{3}$ LinkCare GmbH, Stuttgart, Germany. ${ }^{4}$ Former: Indivior Deutschland GmbH, Mannheim, Germany. ${ }^{5}$ LVR-Hospital Essen, Department of Addictive Behaviour and Addiction Medicine, Medical Faculty, University of Duisburg-Essen, Essen, Germany.

Received: 24 May 2019 Accepted: 11 December 2019

Published online: 16 December 2019

\section{References}

1. Birnbaum H, White A, Schiller M, Waldman T, Cleveland J, Setnik B, et al. Societal costs of opioid abuse, dependence, and misuse in the United States. Value Heal. 2011;12:657-67.

2. Florence CS, Zhou C, Luo F, Xu L. The economic burden of prescription opioid overdose, abuse, and dependence in the United States, 2013. Med Care. 2016:54:901-6.

3. White A, Birnbaum H, Mareva M, Daher M, Vallow S, Schein J, et al. Direct costs of opioid abuse in an insured population in the United States. J Manag Care Pharm. 2005;11:469-79.

4. Kuhn S, Schu M, Vogt I, Schmid M, Simmedinger R, Schlanstedt G, et al. Federal model project for heroin-assisted treatment [Das bundesdeutsche Modellprojekt zur heroingestützten Behandlung Opiatabhängiger - Band 3 Psychosoziale Interventionen - Kosten und Nutzen der Behandlung Transfer in die Versorgung]. Nomos Verlagsgesellschaft. 2008:1-294.

5. Federal Opium Agency. Annual report on the OMT register January 2017 [Bericht zum Substitutionsregister]. 2017.
6. Mattick R, Kimber J, Davoli M. Methadone maintenance therapy versus no opioid replacement therapy for opioid dependence. Cochrane Database Syst Rev. 2003;2:CD002209.

7. Mattick RP, Breen C, Kimber J, Davoli M. Buprenorphine maintenance versus placebo or methadone maintenance for opioid dependence. Cochrane Database Syst Rev. 2014.

8. Auriacombe M, Franques P, Tignol J. Deaths attributable to methadone vs buprenorphine in France. JAMA. 2001;285:45.

9. Soyka M, Apelt SM, Lieb M, Wittchen H-U. One-year mortality rates of patients receiving methadone and buprenorphine maintenance therapy. J Clin Psychopharmacol. 2006;26:657-60.

10. Connock M, Juarez-Garcia A, Jowett S, Frew E, Liu Z, Taylor R. Methadone and buprenorphine for the management of opioid dependence: a systematic review and economic evaluation. Health Technol Assess (Rockv). 2007:11:1-171 iii-iv.

11. Hancock C, Menega H, King N, Andrilla H, E L, Schou P. National Rural Health Association Policy Brief: treating the rural opioid epidemic. National Rural Health Association (NRHA); 2017. p. 1-13.

12. Swart E, Gothe H, Geyer S, Jaunzeme J, Maier B, Grobe T, et al. Good practice of secondary data analysis (GPS): guidelines and recommendations, third revision 2012/2014. Das Gesundheitswes. 2015;77:120-6.

13. Bauhoff S, Fischer L, Göpffarth D, Wuppermann AC. Plan Responses to Diagnosis- Based Payment: Evidence from Germany's Morbidity-Based Risk Adjustment. Munich; 2017. Report No.: 6507.

14. European Monitoring Centre for Drugs and Drug Addiction (EMCDDA). European Drug Report 2017. European Monitoring Centre for Drugs and Drug Addiction (EMCDDA); 2017.

15. Langer K, Wittchen H-U, Bühringer G, Rehm JT. Opioid maintenance treatment of opioid dependent patients: background. Care Structure and Challenges Suchtmed. 2011;13:202-12.

16. Erbas B, Fahrmbacher-Lutz C, Pogarell O, Stecker G, Tauber W, Wodarz N. Guideline for physicians for opioid maintanance treatment in opioid dependent patients, 4th edition [Leitfaden für Ärzte zur substitutionsgestützten Behandlung Opiatabhängiger, 4. vollständig überarbeitete Auflage]. Munich; 2018.

17. German Medical Association Guideline of the German Medical Association fot the execution of opioid maintanance treatment in opioid dependent patients [Richtlinie der Bundesärztekammer zur Durchführung der substitutionsgestützten Behandlung Opioidabhängiger], 02.10.2017. German Medical Association; 2017. p. 1-19.

18. National Association of Statutory Health Insurance Funds (GKV-Spitzenverband) German Pharmacists' Association (DAV). Contract on prices for compounds and preparations of compounds VVertrag über die Preisbildung für Stoffe und Zubereitungen aus Stoffen, Hilfstaxe]. Berlin, Eschborn; 2010. p. 1-27.

19. Wittchen $\mathrm{H}-\mathrm{U}$, Bühringer $\mathrm{G}$, Rehm JT, Soyka M, Träder A, Trautmann S. The social, clinical and treatment situation of opioid maintenance treatment in a prevalence sample of patients at baseline. Suchtmed. 2011;13:227-31.

20. Vogelmann T, Schwarz R, Trümper D. Financing of appropriate treatment and special support of opioid dependence through the morbidity-based risk adjustment system (Morbi-RSA). Monit Versorgungsforsch. 2019;12:65-70.

21. Kähm K, Laxy M, Schneider U, Rogowski WH, Lhachimi SK, Holle R. Health care costs associated with incident complications in patients with type 2 diabetes in Germany. Diabetes Care. 2018:41:971-8.

22. Bode K, Vogel R, Walker J, Kröger C. Health care costs of borderline personality disorder and matched controls with major depressive disorder: a comparative study based on anonymized claims data. Eur J Health Econ. 2017;18:1125-35.

23. Häuser W, Schubert T, Scherbaum N, Tölle T. Guideline-recommended vs high-dose long-term opioid therapy for chronic noncancer pain is associated with better health outcomes. Pain. 2018;159:85-91.

24. Barnett PG. Comparison of costs and utilization among buprenorphine and methadone patients. Addiction. 2009;104:982-92.

25. Srivastava A, Kahan M, Nader M. Primary care management of opioid use disorders: abstinence, methadone, or buprenorphine-naloxone? Can Fam Physician. 2017;63:200-5.

26. National Association of Statutory Health Insurance Pysicians. Uniform Evaluation Scale 2016 [Internet]. Available from: https://www.kbv.de/html/ online-ebm.php

27. Jakovljevic M, Mijailovic Z, Popovska Jovicic B, Canovic P, Gajovic O, Jovanovic M et al. Assessment of viral genotype impact to the cost-effectiveness and overall costs of Care for peg-Interferon-2a + Ribavirine treated chronic hepatitis $C$ patients. Hepat Mon. 2013;13. 
28. Jakovljevic M, Jovanovic M, Rancic N, Vyssoki B, Djordjevic N. LAT Software Induced Savings on Medical Costs of Alcohol Addicts' Care - Results from a Matched-Pairs Case-Control Study. Bruns H, editor. PLoS One. 2014;9:e111931.

29. Hoffmann F, Bachmann CJ. Differences in sociodemographic characteristics, health, and health service use of children and adolescents according to their health insurance funds. Bundesgesundheitsblatt - Gesundheitsforsch Gesundheitsschutz. 2014;57:455-63.

30. Cartwright WS. Cost-benefit analysis of drug treatment services: review of the literature. J Ment Health Policy Econ. 2000;3:11-26.

31. Lieb M, Wittchen H-U, Palm U, Apelt SM, Siegert J, Soyka M. Psychiatric comorbidity in substitution treatment of opioid-dependent patients in primary care: prevalence and impact on clinical features. Heroin Addict Relat Clin Probl. 2010;4:5-16.

32. Soyka M. Treatment of opioid dependence with buprenorphine: current update. Dialogues Clin Neurosci. 2017;19:299-308.

\section{Publisher's Note}

Springer Nature remains neutral with regard to jurisdictional claims in published maps and institutional affiliations.

Ready to submit your research? Choose BMC and benefit from:

- fast, convenient online submission

- thorough peer review by experienced researchers in your field

- rapid publication on acceptance

- support for research data, including large and complex data types

- gold Open Access which fosters wider collaboration and increased citations

- maximum visibility for your research: over $100 \mathrm{M}$ website views per year

At $\mathrm{BMC}$, research is always in progress.

Learn more biomedcentral.com/submissions 